University of Nebraska - Lincoln

DigitalCommons@University of Nebraska - Lincoln

\title{
Lysimetric evaluation of SEBAL using high resolution airborne imagery from BEAREX08
}

\author{
George Paul \\ Kansas State University \\ Prasanna H. Gowda \\ USDA-ARS, prasanna.gowda@ars.usda.gov \\ P.V. Vara Prasad \\ Kansas State University \\ Terry A. Howell \\ USDA-ARS, Terry.Howell@ars.usda.gov \\ Scott A. Staggenborg \\ Kansas State University
}

See next page for additional authors

Follow this and additional works at: https://digitalcommons.unl.edu/usdaarsfacpub

Paul, George; Gowda, Prasanna H.; Prasad, P.V. Vara; Howell, Terry A.; Staggenborg, Scott A.; and Neale, Christopher M.U., "Lysimetric evaluation of SEBAL using high resolution airborne imagery from BEAREX08" (2013). Publications from USDA-ARS / UNL Faculty. 1170.

https://digitalcommons.unl.edu/usdaarsfacpub/1170

This Article is brought to you for free and open access by the U.S. Department of Agriculture: Agricultural Research Service, Lincoln, Nebraska at DigitalCommons@University of Nebraska - Lincoln. It has been accepted for inclusion in Publications from USDA-ARS / UNL Faculty by an authorized administrator of DigitalCommons@University of Nebraska - Lincoln. 


\section{Authors}

George Paul, Prasanna H. Gowda, P.V. Vara Prasad, Terry A. Howell, Scott A. Staggenborg, and Christopher M.U. Neale 


\title{
Lysimetric evaluation of SEBAL using high resolution airborne imagery from BEAREX08
}

\author{
George Paul a $^{\text {, Prasanna H. Gowda }}{ }^{\text {,* }}$, P.V. Vara Prasad ${ }^{a}$, Terry A. Howell ${ }^{\text {b }}$, Scott A. Staggenborg ${ }^{\text {a }}$, \\ Christopher M.U. Neale ${ }^{c}$
}

a Agronomy, 2004 Throckmorton Hall, Kansas State University, Manhattan, KS 66506, USA

${ }^{\mathrm{b}}$ USDA-ARS Conservation and Production Research Laboratory, P.O. Drawer 10, Bushland, TX 79012, USA

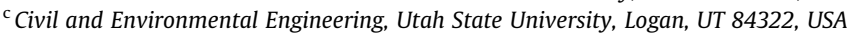

\section{A R T I C L E I N F O}

\section{Article history:}

Received 21 February 2012

Received in revised form 23 May 2013

Accepted 6 June 2013

Available online 17 June 2013

\section{Keywords:}

SEBAL

Evapotranspiration

Airborne remote sensing

Energy balance

Excess resistance

Aerodynamic roughness parameters

\begin{abstract}
A B S T R A C T
In this study, Surface Energy Balance Algorithm for Land (SEBAL) was evaluated for its ability to derive aerodynamic components and surface energy fluxes from very high resolution airborne remote sensing data acquired during the Bushland Evapotranspiration and Agricultural Remote Sensing Experiment 2008 (BEAREX08) in Texas, USA. Issues related to hot and cold pixel selection and the underlying assumptions of difference between air and surface temperature $(d T)$ being linearly related to the surface temperature were also addressed. Estimated instantaneous evapotranspiration (ET) and other components of the surface energy balance were compared with measured data from four large precision weighing lysimeter fields, two each managed under irrigation and dryland conditions. Instantaneous ET was estimated with overall mean bias error and root mean square error (RMSE) of 0.13 and $0.15 \mathrm{~mm} \mathrm{~h}^{-1}$ (23.8 and 28.2\%) respectively, where relatively large RMSE was contributed by dryland field. Sensitivity analysis of the hot and cold pixel selection indicated that up to $20 \%$ of the variability in ET estimates could be attributed to differences in the surface energy balance and roughness properties of the anchor pixels. Adoption of an excess resistance to heat transfer parameter model into SEBAL significantly improved the instantaneous ET estimates.
\end{abstract}

\section{Introduction}

Evapotranspiration (ET) mapping has many applications including crop water management, climate change impact assessment, hydrological modeling, groundwater recharge studies, irrigation performance, and land use planning [1]. At field scales, ET can be measured over a homogenous surface using conventional techniques such as the Bowen ratio (BR), eddy covariance (EC), water balance, and lysimeter systems; however, these systems do not provide spatial trends at the regional scale, especially in heterogeneous landscapes. Generally, large weighing lysimeters are considered the most accurate instrument for direct ET measurement in field [2,3], while the tower based measurements of EC and BR, and water balance methods are commonly employed; each differ in their achievable accuracy range and operational capabilities $[2,4]$. With the advent of earth observing satellites, numerous remote sensing based ET (RS-ET) algorithms were developed and validated. The need for spatial ET mapping was great and therefore it became imperative to keep developing, modifying, and improv-

\footnotetext{
* Corresponding author. Tel.: +1 (806) 356 5730; fax: +1 (806) 3565750.

E-mail address: Prasanna.Gowda@ars.usda.gov (P.H. Gowda).
}

ing these RS-ET algorithms. Surface Energy Balance Algorithm for Land (SEBAL) developed by Bastiaanssen [5] in the early 90's, is considered as one of the important RS-ET algorithms that has continuously evolved and received wide acceptance around the world. According to the developers, by 2005, SEBAL was applied in more than 30 countries for mapping ET [1], indicating that SEBAL is one of the widely used RS-ET algorithms.

Numerous validation studies of SEBAL have taken place involving: (a) satellite sensors with different spatial and spectral image resolutions such as MODIS (Moderate Resolution Imaging Spectroradiometer), AVHRR (Advanced Very High Resolution Radiometer), ASTER (Advanced Spaceborne Thermal Emission and Reflection) and ETM/TM (Enhanced Thematic Mapper); (b) ET measurement techniques with varying accuracy such as BR, EC, lysimeter, and scintillometer; (c) time integration such as instantaneous, daily, monthly, and annual; (d) space integration such as field to watershed scale; and (e) agroclimatic regions. A large number of unique combinations of validation scenarios remain unexplored. In a performance comparison between a two source model (TSM) and SEBAL using airborne sensors, yielded relatively large discrepancies over bare soil and dry/sparsely vegetated areas, where TSM was in better agreement with the observations [6]. Another model 
intercomparison study [7] concluded that SEBAL is highly sensitive to the parameter $k B^{-1}$, leading to large errors for sparsely vegetated drier regions. A summary of SEBAL validation studies provided by Bastiaanssen et al. [1] and numerous other recent studies [8-10] revealed that this algorithm has been extensively applied. However, the range of typical accuracy across these studies corroborated the reported range (67\%-97\%) by review studies [11-13]. SEBAL has come a long way since its inception in 1995 [5] with several variant algorithms' like METRIC (Mapping Evapotranspiration at high Resolution and with Internalized Calibration) [14], SSEB (Simplified Surface Energy Balance) [15], ReSET (Remote Sensing of Evapotranspiration) [16], M-SEBAL (Modified SEBAL) [10], SEBTA (Surface Energy Balance with Topography Algorithm) [17] being developed over the years.

A distinctive approach in SEBAL is the calculation of a single temperature gradient, $d T$ function for the study region using two points denoting the hydrological contrast. The two pixels representing the hydrological contrast were termed as 'Hot' (dry) and 'Cold' (wet) pixels, was first introduced in SEBAL, and adopted into at least five other energy balance algorithms. Hot and cold pixel selection (' $a$ ' and ' $b$ ' coefficients of the temperature gradient function) forms the backbone of SEBAL $[6,8,18]$ and other similar single-source algorithms; however, a very few studies have explored the sensitivity of ' $a$ ' and ' $b$ ' calculation [19] process in SEBAL and how errors are propagated into the ET estimation. In SEBAL, we see two different approaches for handling excess resistance accounting for the discrepancy between aerodynamic $\left(T_{o}\right)$ and radiometric $\left(T_{S}\right)$ temperatures: (i) use of an areal constant $k B^{-1}$ value of 2.3 [6,20-22] and (ii) use of scalar roughness length for heat transfer $\left(z_{\text {oh }}\right.$ or $\left.z_{1}\right)$ value of $0.1[1,23,24,44]$ or 0.01 [8,25-27]. In a study by Long and Singh [28], they concluded that specifying $z_{\text {oh }}$ as 0.1 or introducing a fixed $k B^{-1}$ parameter of 2.3 had appreciable difference in the magnitude of resulting $H$ fluxes. Numerous studies on $k B^{-1}$ can be found in the literature; for more detail, readers can refer to Verhoef et al. [29], Su et al. [30], and Lhomme et al. [31]. It has been categorically stated that for remote sensing based single source bulk transfer schemes, a $k B^{-1}$ parameterization is required $[29,32]$. Furthermore, a widely used $k B^{-1}$ value of 2 has been found to be too low in most cases [29,32,33]. Under both sparse and full vegetation conditions, an appropriate value of $k B^{-1}$ is required for accurate estimation of $H$ using $T_{s}$ [33-35].

Evaluation of uncertainties in remote sensing based models for estimation of surface energy fluxes is not an easy task [19], while at the same time the need for validation studies across hydrological regimes and agroclimatological regions is advocated by review studies [11-13]. Single source models like SEBAL considers the exchange of heat and water in the soil-vegetation-atmosphere continuum as a lumped composite of the underlying surface. Studies have reported the biased performance of single source models in handling extremes in moisture/vegetation cover conditions $[7,36]$. The indigenous approach of SEBAL, in the determination of the temperature gradient using two extreme pixels representing the hydrological end members (wet and dry) has been found to be subjective to analyst decision and domain size $[6,28]$. While the approach of generating single linear temperature gradient function for the complete scene (study region) may be simplistic, however, the uncertainty in surface energy flux estimation resulting from this assumption is very large $[6,8,18]$. Testing and validation of RS-ET algorithms across a range of hydrometeorological and surface cover conditions is important to fill in the existing gap in the operationalization of these algorithms.

The Bushland Evapotranspiration and Agricultural Remote Sensing Experiment 2008 (BEAREX08) conducted during the 2008 summer growing season in Bushland, Texas, provided a unique opportunity to evaluate the turbulent exchange of mass and energy at the land surface. In the past decade, numerous multidisciplinary, multi-institutional, intensive field campaigns includ- ing, Southern Great Plains Hydrology Experiment (SGP97) [37], Exploitation of Angular effects in Land surface observations from satellite (EAGLE 2006) [38], Surface Processes and Ecosystem Changes Through Response Analysis SPECTRA Barrax Campaign (SPARC 2004) [24,39], SENtinel-2 and Fluorescence Experiment (SEN2FLEX 2005) [40], Soil Moisture Atmosphere Coupling Experiment SMACEX [26], and BEAREX07 [41], were undertaken to augment the understanding and improving the parameterization of land surface hydrometeorological processes. These campaigns provide datasets acquired over a diverse hydrological regimes, well suited for evaluating remote sensing based evapotranspiration models.

The main objective of this study was to assess the performance of SEBAL under both dryland and irrigated agricultural conditions in the Texas High Plains using high resolution airborne images. Specific objectives of this evaluation study were to: (a) evaluate the variability in the ' $a$ ' and ' $b$ ' coefficients of the $d T$ function due to the presence of multiple pixels fulfilling the hot and cold pixel selection criteria and how much influence this variability has on the final instantaneous ET ( $\mathrm{ET}_{i}$ ) estimates, (b) compare SEBAL ET estimates with lysimetric data, (c) incorporate a physically based parameterization for excess resistance $\left(k B^{-1}\right)$ into SEBAL and test its performance, and (d) test the relationships to compute the various aerodynamic roughness parameters.

\section{Materials and methods}

SEBAL was applied to five high resolution airborne images and validated against large precision weighing lysimeters. Validation points consisted of two irrigated and two dryland cotton fields situated in the semi-arid Texas High Plains region known for significant advection and nighttime ET [42]. Detailed information on the experimental set-up, algorithm description and evaluation process follows.

\subsection{Study area and data acquisition}

The BEAREX08 was conducted at the USDA-ARS Conservation and Production Research Laboratory (CPRL) during the 2008 summer cropping season. The CPRL is located in Bushland, TX (Fig. 1) with geographic coordinates of $35^{\circ} 11^{\prime} \mathrm{N}, 102^{\circ} 06^{\prime} \mathrm{W}$ and elevation of $1170 \mathrm{~m}$ above mean sea level. It is within the Texas High Plains, where semi-arid climatic conditions and strong advective currents prevail during the summer cropping season. The CPRL has four large weighing lysimeters ( $3 \mathrm{~m}$ long $\times 3 \mathrm{~m}$ wide $\times 2.4 \mathrm{~m}$ deep), each located in the middle of 4.3 ha fields arranged in a block pattern. The two lysimeter fields located on the east (NE and SE) were managed under irrigation and planted to cotton on 21 May, and the other two lysimeters on the west (NW and SW) were under dryland management and planted to cotton on 5 June. Cotton (variety Delta Pine 117) was seeded at 15.8 plants $/ \mathrm{m}^{2}$ on raised beds spaced at $0.76 \mathrm{~m}$. Each lysimeter field was equipped with an automated weather station that provided measurements for net radiation, radiometric surface temperature, soil heat flux, air temperature, relative humidity, and wind speed (refer Chávez et al. [43] for details of field instrumentation). In addition, a grass reference ET weather station field ( $0.31 \mathrm{ha})$, which is a part of the Texas High Plains ET Network was located on the eastern edge of the irrigated lysimeter fields [44] (Fig. 1).

Flying expeditions during BEAREX08 were conducted to collect remotely sensed imagery using the Utah State University (USU) airborne digital multispectral system at high resolutions. The system acquired high resolution imagery in the green $(0.545-$ $0.555 \mu \mathrm{m})$, red $(0.665-0.675 \mu \mathrm{m})$, near infrared $(0.790-0.810 \mu \mathrm{m})$, and thermal infrared $(8-12 \mu \mathrm{m})$ portions of the electromagnetic spectrum. Visible and near infrared images were acquired at $1 \mathrm{~m}$ spatial resolution, and the thermal images were acquired at $3 \mathrm{~m}$. 


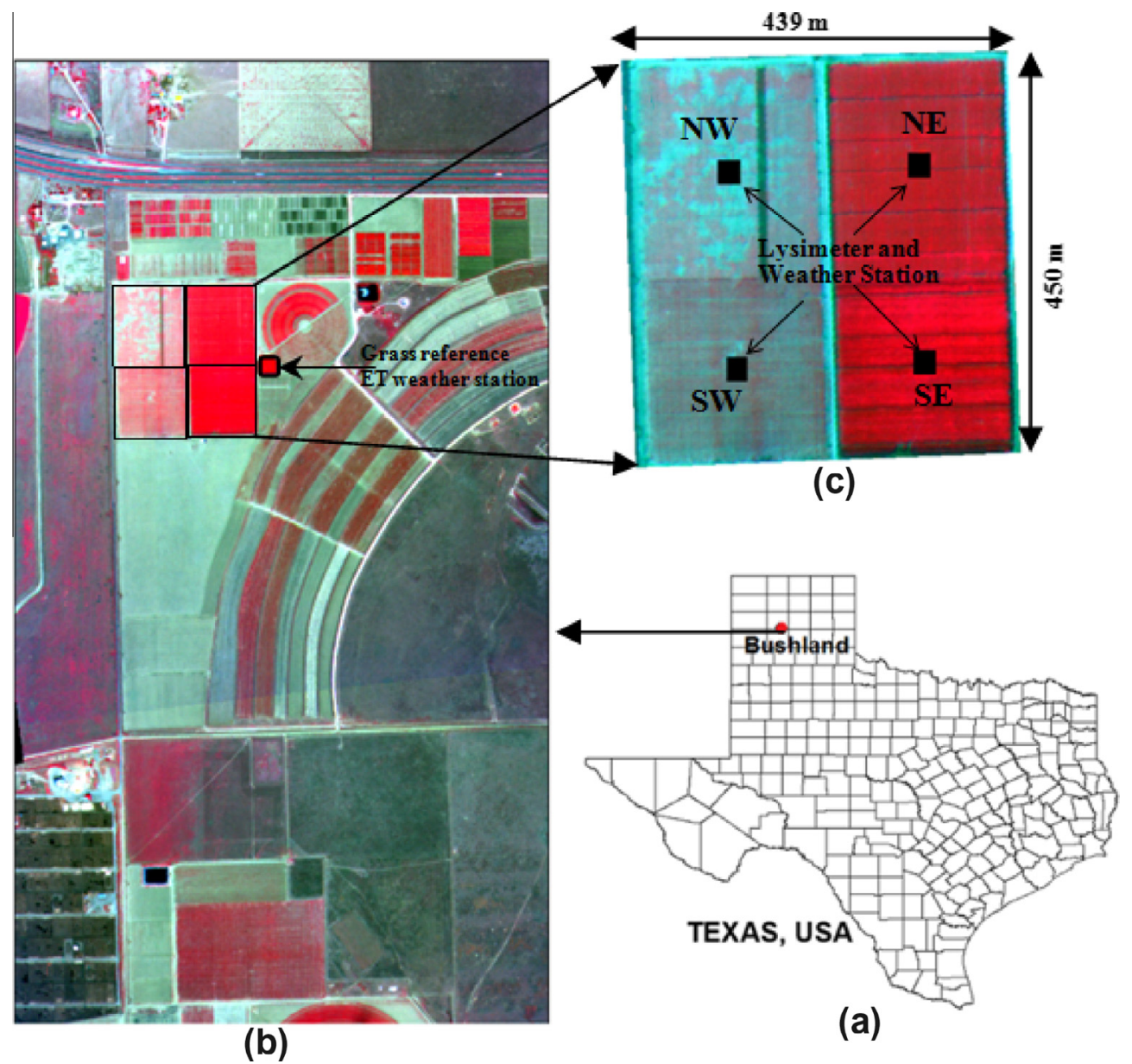

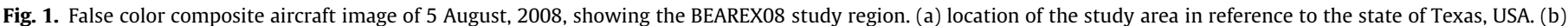
aircraft scene covering a region of close to $5 \mathrm{~km}^{2}$ and (c) exploded view of the lysimeter field.

Five images were acquired from early to mid-cropping season for dates June 26 (178), July 12 (194), July 20 (202), July 28 (210), and August 5 (218). All images were acquired close to 12 noon central standard time from an altitude of $2000 \mathrm{~m}$ agl (above ground level). Description of the post processing including geometric corrections, radiometric calibration and atmospheric correction can be found in Neale et al. [45]. SEBAL was coded using Python programming language and executed in the Arc-GIS 10.0. The five images provided conditions from a near bare soil situation to near complete canopy cover. Fig. 2 shows the digital picture of the field taken on 26 June and 5 August. On 26 June, only isolated seedlings are seen on both irrigated and dryland fields, and the surface is dominated by bare soil. On 5 August, the crops in the irrigated field had attained a near complete canopy, whereas, the dryland fields exhibited high reflectance from soil. The lysimeter fields were considered homogeneous, and the center of the field with the lysimeter and instrument cluster was used to validate all the estimates. A $12 \times 12\left(\mathrm{~m}^{2}\right)$ pixel grid covering the lysimeter location was marked (in the image) in all 4 lysimeter fields to extract average values of estimated ET, net radiation, soil heat flux, surface temperature and aerodynamic parameters. The performance statistics used for the evaluation of surface energy fluxes and instantaneous ET are provided in Table 1.

\subsection{SEBAL}

Two versions of SEBAL, SEBAL2000 and SEBAL2008 have been identified by the developers with claims of several unpublished ad- vances incorporated into the later version [18]. In this study, we have used the published SEBAL (SEBAL2000 and SEBAL2008) versions and efforts were made to report the sub-models and approaches taken.

SEBAL utilizes the widely applied residual approaches of surface energy balance to estimate ET at different temporal and spatial scales. The net energy coming from the sun and atmosphere in the form of short- and long-wave radiation is transformed and used for (a) heating the soil (soil heat flux into the ground), (b) heating the surface environment (sensible heat flux to the atmosphere), and (c) transforming water into vapor (latent heat flux from the crop/soil surfaces). All the energy involved in the soil-vegetation-atmosphere interface can be given as the Energy Balance (EB) equation:

$R_{n}=G_{0}+H+L E$

where, $R_{n}$ is the net radiation, $G_{o}$ is the soil heat flux, $H$ is the sensible heat flux, and $L E$ is the latent heat flux, with all units expressed in $\mathrm{W} \mathrm{m}^{-2}$. Latent heat was expressed as hourly ET ( $\mathrm{mm}$ ) (by dividing $L E$ by the latent heat of vaporization and the density of water and multiplying by $\left.3600 \mathrm{~s} \mathrm{hr}^{-1}\right)$. Net radiation $\left(R_{n}\right)$ expressed as an electromagnetic balance of all incoming and outgoing fluxes, which constitutes a key driver for heating the atmosphere and the ground, is given by:

$R_{n}=S \downarrow-S \uparrow+L \downarrow-L \uparrow=\left(1-\alpha_{s}\right) S \downarrow+\varepsilon_{a} \sigma T_{a}^{4}-\varepsilon_{s} \sigma T_{s}^{4}$

In Eq. (2), $S$ denotes short-wave radiation $(0.3-3 \mu \mathrm{m})$ and $L$ is the long-wave radiation $(3-100 \mu \mathrm{m})$. The arrows show the direction of the flux entering $(\downarrow)$ or leaving $(\uparrow)$ the system. Each term 

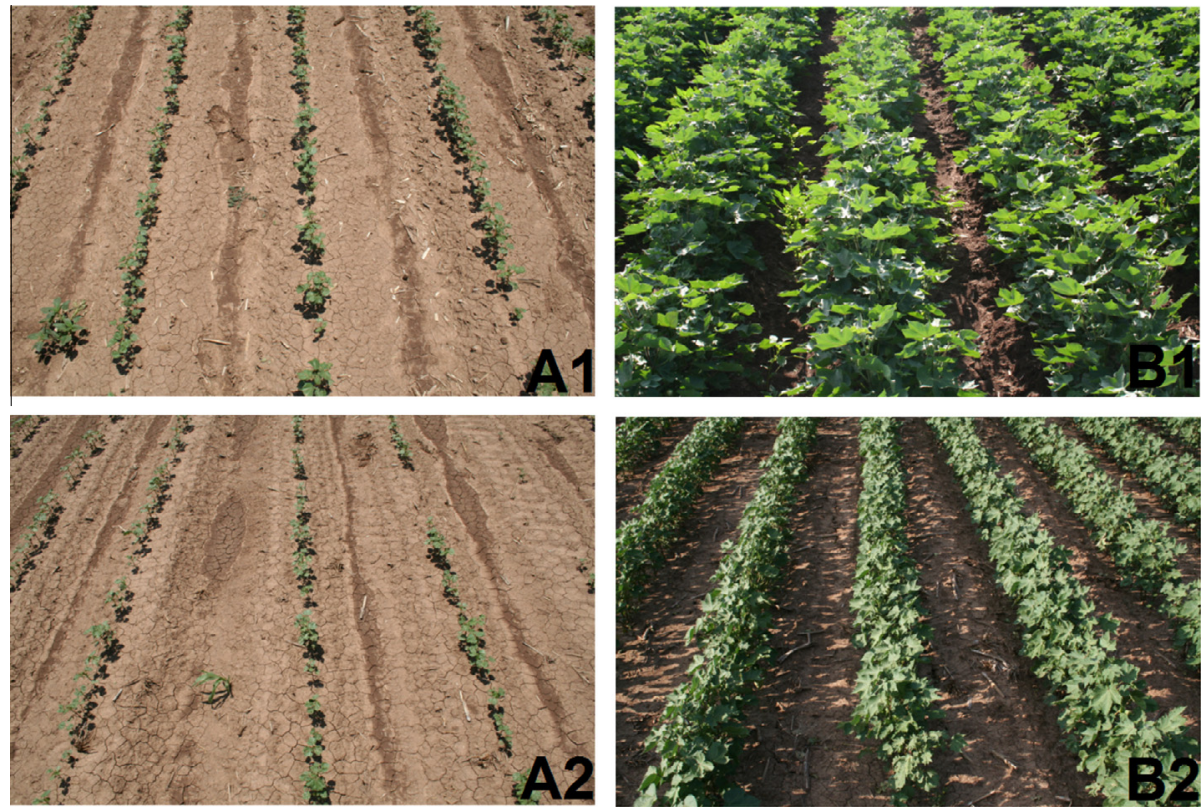

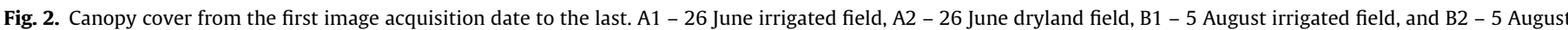
dryland field.

Table 1

Performance statistics used for evaluating model performance.

\begin{tabular}{|c|c|c|c|}
\hline $\begin{array}{l}\text { Statistical } \\
\text { variable }\end{array}$ & Description & Equation & Use and desired value \\
\hline$n$ & Number of observations & - & - \\
\hline$R^{2}$ & Coefficient of determination & $\frac{\left(\sum_{i=1}^{n}\left(O_{i}-\bar{O}\right)\left(M_{i}-\bar{m}\right)\right)^{2}}{\sum_{i=1}^{n}\left(O_{i}-\bar{O}\right)^{2} \cdot \sum_{i=1}^{n}\left(M_{i}-\bar{M}\right)^{2}}$ & Degree of collinearity +1 or -1 \\
\hline$m$ & Slope of the best fit regression line & $\frac{M_{1}-M_{2}}{O_{1}-O_{2}}$ & Relative relationship between modeled and observed value $\sim 1$ \\
\hline$y$-intercept & $\begin{array}{l}y \text {-intercept of the best fit regression } \\
\text { line }\end{array}$ & - & Lag or lead indicator $\sim 0$ \\
\hline MBE & Mean bias error & $\frac{1}{N} \sum_{i=1}^{n}\left(O_{i}-M_{i}\right)$ & $\begin{array}{l}\text { Error in the constituents unit with underestimation/overestimation indication } \\
\sim 0\end{array}$ \\
\hline PBIAS & Percentage bias & $\frac{\sum_{i=1}^{n}\left(O_{i}-M_{i}\right)}{\sum_{i}^{0}} \times 100$ & Bias expressed as percentage error $\sim 0$ \\
\hline RMSE & Root mean square error & $\sqrt{\frac{1}{N}} \sum_{i=1}^{n}\left(M_{i}-O_{i}\right)^{2}$ & Indicates error in the constituents unit $\sim 0$ \\
\hline \% RMSE & Percentage root mean square error & $\frac{R M S E}{\frac{\sum_{i=1}^{n} o_{i}}{n}} \times 100$ & RMSE expressed as percentage deviation from mean $\sim 0$ \\
\hline NSE & Nash-Sutcliffe efficiency & $\frac{\sum_{i=1}^{n}\left(O_{i}-\bar{O}\right)^{2}-\sum_{i=1}^{n}\left(M_{i}-O_{i}\right)^{2}}{\sum\left(O_{i}-\bar{O}\right)^{2}}$ & Indicative of the strength of model to predict the observed $\sim 0-1$ \\
\hline
\end{tabular}

$O_{i}$ - observed value; $M_{i}$ - Modeled value; $\bar{O}$ - mean of the observed, $\bar{M}$ - mean of the modeled.

in Eq. (2) can be either determined directly from models or obtained from the ground weather station. The incoming short-wave radiation $(S \downarrow)$ and the air temperature $\left(T_{a}\right)$ are measured at weather stations. $T_{s}$ is the surface radiometric temperature obtained from the inversion of Plank's law in 10-12 $\mu \mathrm{m}$ band width. Other terms in Eq. (2) are broadband surface albedo $\left(\alpha_{s}\right)$, apparent emissivity of atmosphere $\left(\varepsilon_{a}\right)$, surface emissivity $\left(\varepsilon_{s}\right)$, and the Stefan-Boltzmann constant $\left(\sigma=5.67 \mathrm{E}-08 \mathrm{~W} \mathrm{~m}^{-2} \mathrm{~K}^{-4}\right)$. Because low flying airborne images were used with primary atmospheric corrections, the need for converting planetary albedo into surface albedo was evaded and planetary broadband albedo $\left(\alpha_{p}\right)$ was considered equivalent to the surface broadband albedo $\left(\alpha_{s}\right)$.

Broadband planetary albedo $\left(\alpha_{p}\right)$ was calculated as the sum of the individual in-band planetary albedos with different weighing factors. The weighing factor for each band is proportional to its solar exoatmospheric irradiance $\left(\operatorname{ESUN}_{\lambda}\right)$ which is an average solar irradiance weighted by the corresponding spectral band response function. The weight for each band was calculated and the equation for broadband planetary albedo $\left(\alpha_{p}\right)$ was derived as:

$\alpha_{p}=0.303$ green +0.400 red +0.296 NIR

where green, red, and NIR are the reflectance of the respective bands.

The apparent emissivity of the atmosphere was estimated from equations based on vapor pressure and air temperature at the standard meteorological stations. For clear skies, the Brutsaert [46] formulation was used as:

$\varepsilon_{a}=0.892\left(\frac{e_{a}}{T_{a}}\right)^{1 / 7}$

where $e_{a}$ is vapor pressure near the surface (actual vapor pressure) in $\mathrm{kPa}$ and $T_{a}$ is in Kelvin. Actual vapor pressure $\left(e_{a}\right)$ can be calculated from relative humidity and air temperature at reference level as: 
$e_{a}=\frac{R H}{100 e_{s}}$

where $e_{a}$ is in $\mathrm{kPa}$ and $e_{s}$ is the saturation vapor pressure in $\mathrm{kPa}$ given by:

$e_{s}=0.6108 \exp \left(\frac{17.27 \times T_{a}}{T_{a}+237.3}\right)$

$T_{a}$ is the air temperature in degree Celsius $\left({ }^{\circ} \mathrm{C}\right)$.

The surface emissivity $\left(\varepsilon_{s}\right)$ is calculated from NDVI (Normalized Difference Vegetation Index) as given by Van de Griend and Owe [47]:

$\varepsilon_{s}=1.009+0.047 \ln (\mathrm{NDVI})$

The above relationship is valid only for NDVI values over 0.16 For NDVI values below 0.16 (usually bare soils), emissivity was assumed to be 0.92 and for NDVI values below -0.1 (usually water), it was assumed to be 1.0.

The mathematical formulation of $H$ is based on the single source resistance scheme of mass transport of heat and momentum between the surface and the overlying atmosphere. $H$ is directly related to the difference between the surface aerodynamic temperature $\left(T_{o}\right)$ and above canopy air temperature $\left(T_{a}\right)$ :

$H=\rho_{a} C_{p} \frac{T_{o}-T_{a}}{r_{a h}}$

where $\rho_{a}$ is the density of air $\left(\sim 1.17 \mathrm{~kg} \mathrm{~m}^{-3}\right), C_{p}$ is the air specific heat at constant pressure $\left(\sim 1.005 \mathrm{~J} \mathrm{~kg}^{-1} \mathrm{~K}^{-1}\right)$, and $r_{a h}$ is the aerodynamic resistance to heat between the surface and the reference level $\left(\mathrm{s} \mathrm{m}^{-1}\right)$. Since $T_{o}$ cannot be measured directly at source height, in single-source models the radiometric surface temperature $\left(T_{s}\right)$ measured by the remote sensing thermal sensors, is used as a surrogate. To accommodate this approximation, a dimensional parameter for excess resistance to heat transfer $\left(k B^{-1}\right)$ is incorporated into the calculation of $r_{a h}$. Studies [32,33] have shown that if an appropriate value of $k B^{-1}$ is determined, $H$ can be estimated accurately using $T_{s}$. The SEBAL model has used an areal constant $k B^{-1}$ value of 2.3 for all surfaces and emphasized that the approach of hot and cold pixel for scaling thermal inertia would reduce the consequences of aerodynamic temperature inaccuracy on $H$ estimation [20]. The classical aerodynamic resistance to heat transfer $\left(r_{a h}\right)$ equation is given by

$r_{a h}=\frac{1}{k u_{*}}\left[\ln \left(\frac{z_{\text {ref }}-d_{o}}{z_{o h}}\right)-\psi_{h}\right]$

where $u_{*}$ is the friction velocity defined by

$u_{*}=\frac{k u_{b}}{\ln \left[\frac{z_{b}-d_{o}}{z_{o m}}\right]-\psi_{m}}$

The $d_{o}$ is the zero plane displacement height, $z_{o m}$ is the roughness length for momentum transport, $z_{o h}$ is the roughness length for heat transport, $z_{\text {ref }}(2 \mathrm{~m})$ is the reference level at which the wind speed $\left(u_{r e f}\right)$ and $T_{a}$ are measured, $k$ is the von Karman's constant ( $\sim 0.41), z_{b}$ is the blending height $(100 \mathrm{~m}), u_{b}$ is the wind speed at blending height, and $\psi_{h}$ and $\psi_{m}$ are the stability correction functions for heat and momentum as a function of Monin-Obukhov length $(L)$. Equations developed by Paulson [48] were used to determine $\psi_{h}$ and $\psi_{m}$. Sensible heat flux $(H)$ can be calculated from Eqs. (8)-(10) by simultaneously solving for the stability functions through an iterative process. Soil heat flux was derived from the relationship developed by Bastiaanssen et al. [20], given as:

$G_{o}=\left[\frac{\left(T_{s}-273.15\right)}{100 \alpha_{s}}\left(c_{1} \alpha_{s}+c_{2} \alpha_{s}^{2}\right)\left(1-0.98 \mathrm{NDVI}^{4}\right)\right] \cdot R_{n}$

where $c_{1}$ and $c_{2}$ are locally calibrated coefficients with values of 0.12 and 0.42 , respectively. Other variables in Eq. (11) such as $d_{o}$, $z_{o m}, u_{b}$, and $k B^{-1}$ can be solved with either empirical or physically based models. Appendix A lists the various parameterizations used in the intermediate steps.

\subsection{The excess resistance parameter $\left(k B^{-1}\right)$}

In Eq. (8), the aerodynamic temperature $T_{o}$, is defined as the air temperature at effective height of the canopy at which the vegetation component of $H$ and $L E$ fluxes arise given by $d_{o}+z_{o h}$ [49]. From the Monin-Obukhov (M-O) similarity theory, the aerodynamic resistance, $r_{a h}$, is defined as the resistance from height $z_{o h}+d_{o}$ having an aerodynamic temperature, to the height $z_{\text {ref. }}$ Eq. (9) can be written as:

$r_{a h}=r_{a}+r_{r}=\frac{1}{k u_{*}}\left[\ln \left(\frac{z-d_{o}}{z_{o m}}\right)-\psi_{h}\right]+\frac{1}{k u_{*}} \ln \left(\frac{z_{o m}}{z_{o h}}\right)$

where, $r_{a}$ is the aerodynamic resistance between the air temperature at a height $d_{o}+z_{o m}$ and the reference height $\left(z_{\text {ref }}\right)$. The formulation of $H$ using the definition of $T_{o}$ requires an additional resistance called the excess resistance and denoted by $r_{r}$ in Eq. (12). Following many authors [49,50], it is surmised that the aerodynamic resistance to heat transfer $\left(r_{a h}\right)$ is greater than aerodynamic resistance for momentum transfer $\left(r_{a}\right)$. Consequently, the roughness length for heat transfer $\left(z_{o h}\right)$ is lower than the roughness length for momentum transfer $\left(z_{o m}\right)$. The excess resistance $\left(r_{r}\right)$ is an integral part of the aerodynamic resistance formulation (Eq. (12)) and takes into account the fundamental difference in the mechanism determining heat and momentum transfer. It is important to understand that the excess resistance is attached to the aerodynamic temperature, however, a practical problem arises when neither the $T_{o}$ nor the $z_{\text {oh }}$ could be measured. An alternative is to use the radiometric surface temperature from the infrared sensors as a surrogate for $T_{o}$ and to accommodate this substitution a correction is performed on the excess resistance term. Excess resistance $\left(r_{r}\right)$ formulation from Eq. (12) can be written as:

$r_{r}=\frac{1}{k u_{*}} \ln \left(\frac{z_{o m}}{z_{o h}}\right)$

Eq. (13) is commonly expressed as a function of the dimensionless bulk parameter $B^{-1}[51]$ :

$r_{r}=\frac{B^{-1}}{u_{*}}$

The parameter $k B^{-1}$ is related to roughness height for heat $z_{o h}$, by combining Eqs. (13) and (14), as:

$k B^{-1}=\ln \left[\frac{z_{o m}}{z_{o h}}\right]$

It must be emphasized here that $k B^{-1}$ is the parameter describing the excess resistance and should not be confused with the excess resistance $\left(r_{r}\right)$. In context to heat transfer estimation from $T_{s}$, $k B^{-1}$ is a mere fitting parameter no longer connected to its theoretical background and largely an empirical parameter $[31,51]$.

In SEBAL, the $k B^{-1}$ value of 2.3 [20] sets the value of roughness length for heat to $1 / 10$ of roughness length for momentum. Several studies have shown that the value of $k B^{-1}$ can range from 1 to 10 depending on the dominant surface cover [30,32,33,52]. A physically based model for $z_{o h}$ expressed in terms of $k B^{-1}$ was incorporated into SEBAL to see its influence on the estimation of ET. The $k B^{-1}$ model developed by Su et al. [30] that consists of terms representing the contribution of the soil alone, the canopy and the canopy-soil interaction to resistance to heat transfer (Appendix B) was selected. 


\subsection{Aerodynamic roughness parameters}

Roughness height for momentum $\left(z_{\text {om }}\right)$ greatly influences the turbulent characteristics near the surface where the heat fluxes originate. The $z_{\text {om }}$ depends on various factors such as wind direction, vegetation height, canopy cover, vegetation type, and row spacing. Estimating these factors using an empirical equation as a function of NDVI might be an over simplification; however, such estimates are reasonably accurate for uniform cover and fairly flat terrains [50]. Although remote sensing observations provide vegetation information, estimation of roughness height remains a challenge for regional modeling of turbulent transport because of highly variable topographic and canopy structures, and wind behaviors. There are numerous methods to retrieve this parameter including wind profile methods, vegetation height, lookup table based on the land use classification, and empirical relationship using NDVI. Calibrating the empirical relationship for the study region from the data collected during the campaign would be the best available option. The following exponential relationship derived using NDVI and crop height information [5] was used to estimate $z_{o m}$

$$
z_{\text {om }}=\exp \left(C_{1}+C_{2} \mathrm{NDVI}\right)
$$

where $C_{1}$ and $C_{2}$ are regression constants derived separately for each image from a plot of $\ln \left(z_{o m}\right)$ versus NDVI for pixels representing varied vegetation heights and extremes of NDVI (Fig. 3). For generating the relationship, $z_{\text {om }}$ was calculated from the height of vegetation $\left(z_{\text {om }}=0.13 \mathrm{~h}\right)$ [53] recorded for different crops during the campaign. One single set of coefficients for all five images, $C_{1}=-5.5$ and $C_{2}=5.8$, from [5] was used to test the coefficient's sensitivity on the ET estimation.

\subsection{Selection of a dry (hot) and wet (cold) pixel}

SEBAL uses the extreme pixels of the image (dry and wet pixel), to develop a relationship between $T_{S}$ and the difference between $T_{o}$ and $T_{a}$ given in the form of:

$T_{o}-T_{a}=d T=a+b \cdot T_{s}$

where ' $a$ ' and ' $b$ ' are the regression constants. The basic assumption behind this relationship is that the difference between $T_{o}$ and $T_{a}$ is linearly related to the $T_{s}$. A second assumption of the existence of

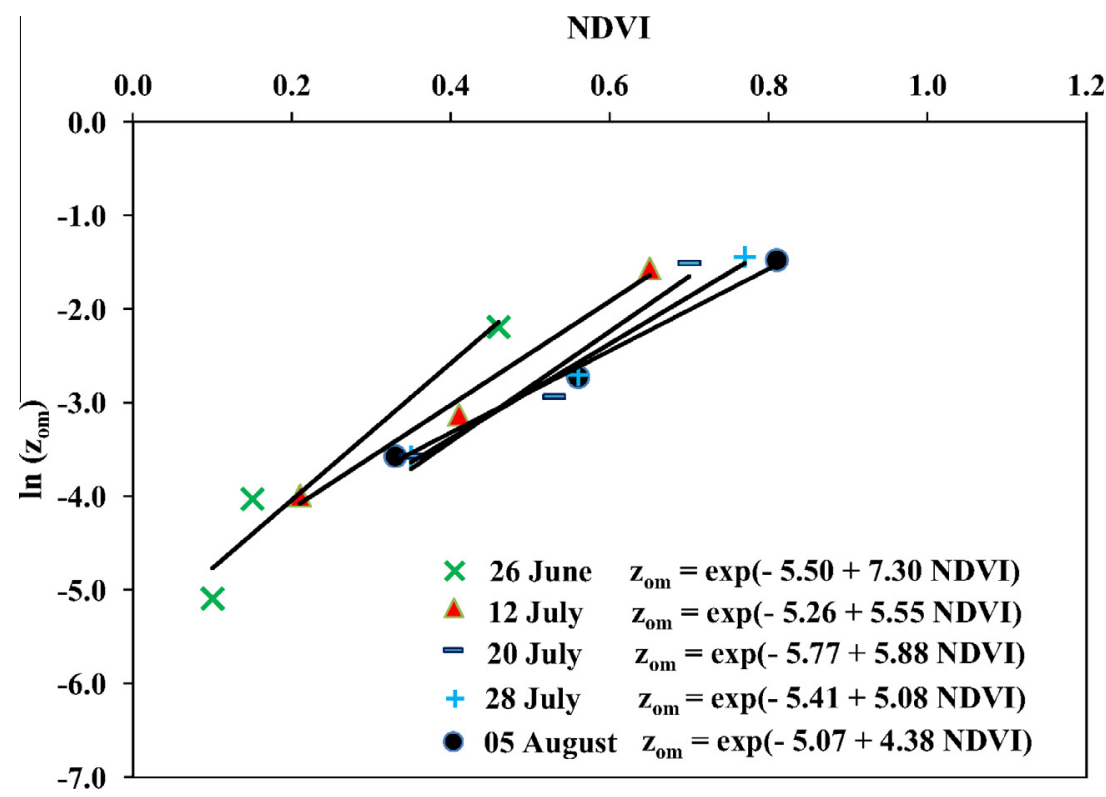

Fig. 3. Relationship for roughness length for momentum transport generated from plant height information for each image.

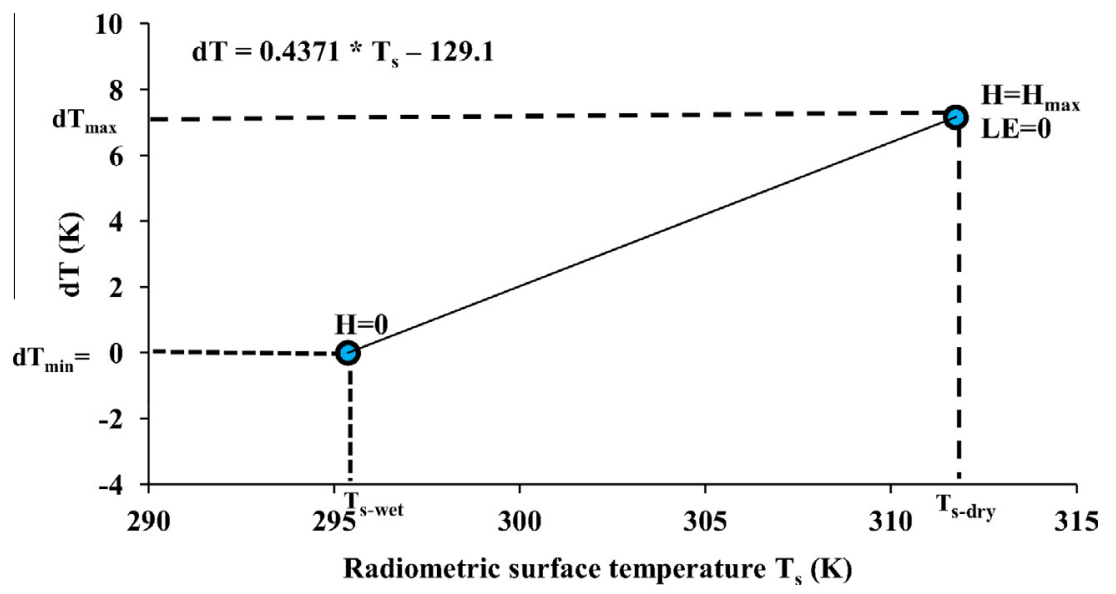

Fig. 4. Solving for coefficients ' $a$ ' and ' $b$ ' using the wet and dry pixel concept. 
hydrological contrast (dry and wet area) in the study region must be implemented. Fig. 4 illustrates the process of deriving the coefficients from extreme dry and wet pixels. For the wet pixel, $d T$ was considered zero while for the dry pixel, $d T$ was iteratively determined by Eqs. ((8)-(10)) adjusting for the stability functions. Physically, the wet pixel should be the surface transpiring at its potential limit $\left(L E=L E_{\max }\right.$ and $H=0$ ), and therefore $d T=0$. The ideal location of a wet pixel is a surface with full canopy vegetation growing under no soil moisture limitation. A dry pixel physically represents a surface with dry conditions and ET equal to zero. ( $L E=0$ or $H=H_{\max }=R_{n}-G_{o}$ ). Ideally, bare soil with no residual moisture for evaporation should fit the dry pixel requirements. Selection of these two extreme pixels in the image causes a bottleneck in the implementation of SEBAL as it involves a subjective decision of the analyst. Generally, the wet pixel is selected on the criteria of low temperature and high NDVI, whereas the dry pixel is characterized by high temperature, low NDVI, and low albedo. Scatter plots of NDVI- $T_{s}$ and albedo- $T_{s}$ along with histograms have been used to identify the group of pixels fulfilling the extreme pixel criteria [6,9]; however, these methods do not help in secluding a single set of pixels, which again largely depends on the analyst's decision. Furthermore, different sets of pixels fulfilling the dry and wet pixel criteria may exhibit entirely different surface energy balance and roughness properties and lead to variations in the ' $a$ ' and ' $b$ ' coefficients. In the present study, we harnessed the capability of the GIS environment wherein classification, histogram generation, and overlaying of the surface temperature, NDVI, and albedo maps could be done easily, leading to identification of a group of pixels that fulfilled the criteria. The identification of the wet pixel was easier because of the presence of a grass reference ET weather station in the study region (Fig. 1) that typically exhibited the lowest surface temperature and greatest NDVI for all five images. Selection of the hot pixel was not easy because multiple pixels satisfied the conditions. We selected three sets of hot pixels well spread in the study domain to test the variations in the determination of ' $a$ ' and ' $b$ ' coefficients and further its influence on final ET estimation.

\section{Results and discussion}

\subsection{Net radiation, soil heat flux and surface temperature}

Performance statistics for $R_{n}, G_{0}$, and $T_{s}$ for the complete data set ( $n=20$ ) are provided in Table 2 . The $T_{s}$ retrieved from the airborne thermal images was compared against the observed IRT (infra-red thermometer) values with a small RMSE value of $1.16^{\circ} \mathrm{C}(3.36 \%)$. It is within the range of $T_{s}$ values $\left(1-1.5^{\circ} \mathrm{C}\right)$ reported in the literature for thermal imagery acquired from various airborne and satellite platforms [40]. Net radiation was under predicted with a small RMSE of $17.98 \mathrm{~W} \mathrm{~m}^{-2}$ (3.1\%) and an MBE of $6.61 \mathrm{~W} \mathrm{~m}^{-2}(1.14 \%)$, which was well within the typical error range of $5 \%-10 \%$ $\left(\sim 30-60 \mathrm{~W} \mathrm{~m}^{-2}\right)[6,8,9]$ and most instrument measurement uncertainty [54]. The $R_{n}$ estimates were comparable to those observed by Jacob et al. [22], who attributed the low $R_{n}$ estimation errors to use of relatively accurate albedo estimates derived from aircraft data. An overestimation error of $9.87 \mathrm{~W} \mathrm{~m}^{-2}$ (36.2\%) and RMSE of $13.5 \mathrm{~W} \mathrm{~m}^{-2}(49.6 \%)$ was recorded for $G_{o}$ estimates. A large discrepancy was evident from the low $R^{2}$ value, with negative NSE indicating the model's unsatisfactory performance in estimating $G_{0}$. Similar results with RMSE ranging from 20 to $40 \mathrm{~W} \mathrm{~m}^{-2}$ have been reported by various studies $[8,22]$ for the present parameterization (Eq. (11)) using NDVI and $R_{n}$. Although $G_{o}$ estimates were not accurate, it was not a major concern because the magnitude of error was small $\left( \pm 13 \mathrm{~W} \mathrm{~m}^{-2}\right)$ and was expected to have negligible effect on the ET estimates. Moreover, the available energy $\left(R_{n}-\right.$ $-G_{o}$ ) for convective fluxes resulting from the underestimation of $R_{n}$ and overestimation of $G_{o}$ was $16.5 \mathrm{~W} \mathrm{~m}^{-2}$ (MBE), which was a small underestimation. Nevertheless, several causes can explain the poor performance of $G_{o}$ estimates in the evaluation's statistics including the spatial variability of $G_{o}$, inaccuracies in the soil heat flux plate measurements and the limitations of NDVI based $G_{o}$ parameterization.

\subsection{ET flux variability due to selection of different dry and wet pixel end members}

Three sets of ' $a$ ' and ' $b$ ' coefficients generated per image with their temperature, NDVI, albedo, and roughness properties are presented in Table 3. It is evident from the Table 3 that end member pixels of particular image exhibiting same temperature could still produce a different set of coefficients owing to their different surface energy balance and roughness properties. SEBAL was executed for each set of ' $a$ ' and ' $b$ ' coefficients, and the estimated instantaneous ET was analyzed using standard deviation and coefficient of variation (Table 4). The coefficient of variation (CV in\%; $\mathrm{SD} \times 100 /$ Mean) for the irrigated lysimeter fields (SE and NE, Fig. 1) ranged from 0 to $22 \%$ while for the dryland lysimeter fields (NW and SW, Fig. 1), the CV ranged from 4 to $80 \%$. Consistently larger deviations (CV) were associated with dryland (sparse vegetation) $\mathrm{ET}_{i}$ estimations compared with irrigated fields (more complete vegetative cover). The reason for this biased behavior of the algorithm for irrigated (full cover) and dryland (sparse cover) cropping systems lies in the fact $T_{s}-T_{o}$ is minimal for full cover canopies [49], and a nominal correction of $2.3\left(\mathrm{kB}^{-1}\right)$ provide good ET estimates [33]. However, on sparse canopy cover, the $T_{s}-T_{o}$ is always greater, and the correction applied $\left(k B^{-1}=2.3\right)$ could not account for the larger differences, thus providing unreliable ET estimates. This shows that the temperature gradient relationship cannot completely address the spatial variability of $k B^{-1}$. Therefore, inherent assumption that hot and cold pixel for scaling thermal inertia $(d T)$ accommodates the consequences of aerodynamic temperature inaccuracy on $H$ estimation may not be true.

\subsection{Instantaneous ET by SEBAL}

For each image, the average $\mathrm{ET}_{i}$ derived from the three set of ' $a$ ' and ' $b$ ' was compared against lysimeter values for the performance evaluation of SEBAL. Evaluation statistics for the complete data set as well as for the irrigated and dryland fields are presented separately in Table $5 \mathrm{a}$ for thorough evaluation. An overall RMSE of $0.15 \mathrm{~mm} \mathrm{~h}^{-1}$ (28.1\%) and MBE of $0.13 \mathrm{~mm} \mathrm{~h}^{-1}$ (23.8\%) were observed for $\mathrm{ET}_{i}$ estimates from all four lysimeter fields. The positive bias indicated underestimation of $\mathrm{ET}_{i}$. This result is similar to the

Table 2

Performance statistics for $T_{s}\left(\right.$ Obs. Mean: $\left.34.4^{\circ} \mathrm{C}\right), R_{n}\left(\right.$ Obs. Mean: $579 \mathrm{~W} \mathrm{~m}^{-2}$ ), and $G_{o}\left(\right.$ Obs. Mean: $\left.27 \mathrm{~W} \mathrm{~m}^{-2}\right)($ No. of observations $=20)$.

\begin{tabular}{|c|c|c|c|c|c|c|c|c|c|}
\hline \multirow[t]{2}{*}{ Estimated parameter } & \multirow[t]{2}{*}{ Mean } & \multirow[t]{2}{*}{ MBE } & \multirow[t]{2}{*}{ PBIAS } & \multirow[t]{2}{*}{ RMSE } & \multirow[t]{2}{*}{ \%RMSE } & \multirow[t]{2}{*}{ NSE } & \multicolumn{3}{|c|}{ Regression } \\
\hline & & & & & & & $R^{2}$ & $m$ & $y$-intercept \\
\hline$T_{s}\left({ }^{\circ} \mathrm{C}\right)$ & 34.3 & 0.04 & 0.13 & 1.16 & 3.36 & 0.96 & 0.96 & 0.95 & 1.59 \\
\hline$R_{N}\left(\mathrm{~W} \mathrm{~m}^{-2}\right)$ & 573 & 6.61 & 1.14 & 17.98 & 3.10 & 0.86 & 0.91 & 1.10 & -65.04 \\
\hline$G_{S}\left(\mathrm{~W} \mathrm{~m}^{-2}\right)$ & 37 & -9.87 & -36.24 & 13.51 & 49.58 & -3.96 & 0.02 & 0.18 & 32.19 \\
\hline
\end{tabular}


Table 3

Selection of hot and wet pixel and the variability in the ' $a$ ' and ' $b$ ' coefficient.

\begin{tabular}{|c|c|c|c|c|c|c|c|c|}
\hline \multirow[t]{2}{*}{ Image acquisition date } & \multicolumn{2}{|c|}{ Cold/wet pixel } & \multicolumn{4}{|c|}{ Hot/dry pixel } & \multicolumn{2}{|c|}{$d T=a+b T_{s}$} \\
\hline & $T_{\text {wet }}$ & NDVI & $T_{d r y}$ & NDVI & Albedo & $z_{\text {om }}$ & $a$ & $b$ \\
\hline \multirow{3}{*}{26 June, 2008} & 301.09 & 0.704 & 315.42 & 0.143 & 0.162 & 0.012 & -198.46 & 0.659 \\
\hline & 301.09 & 0.704 & 315.42 & 0.122 & 0.180 & 0.010 & -199.25 & 0.662 \\
\hline & 301.09 & 0.704 & 315.98 & 0.153 & 0.185 & 0.013 & -177.12 & 0.588 \\
\hline \multirow{3}{*}{12 July, 2008} & 295.36 & 0.805 & 310.14 & 0.165 & 0.168 & 0.013 & -172.07 & 0.582 \\
\hline & 295.36 & 0.805 & 310.50 & 0.162 & 0.151 & 0.013 & -172.41 & 0.583 \\
\hline & 295.36 & 0.805 & 311.74 & 0.206 & 0.220 & 0.016 & -129.09 & 0.437 \\
\hline \multirow[t]{3}{*}{20 July, 2008} & 297.47 & 0.790 & 317.42 & 0.232 & 0.178 & 0.012 & -185.71 & 0.624 \\
\hline & 297.47 & 0.790 & 316.94 & 0.138 & 0.172 & 0.007 & -227.04 & 0.763 \\
\hline & 297.47 & 0.790 & 316.99 & 0.176 & 0.166 & 0.009 & -215.83 & 0.725 \\
\hline \multirow[t]{3}{*}{28 July, 2008} & 299.08 & 0.799 & 317.37 & 0.152 & 0.185 & 0.010 & -220.95 & 0.738 \\
\hline & 299.08 & 0.799 & 317.28 & 0.197 & 0.181 & 0.012 & -201.89 & 0.675 \\
\hline & 299.08 & 0.799 & 317.37 & 0.155 & 0.188 & 0.009 & -212.95 & 0.712 \\
\hline \multirow[t]{3}{*}{05 August, 2008} & 300.50 & 0.800 & 334.35 & 0.152 & 0.161 & 0.012 & -143.79 & 0.478 \\
\hline & 300.50 & 0.800 & 334.59 & 0.150 & 0.146 & 0.012 & -147.22 & 0.489 \\
\hline & 300.50 & 0.800 & 335.45 & 0.157 & 0.149 & 0.013 & -138.32 & 0.460 \\
\hline
\end{tabular}

Table 4

Influence of ' $a$ ' and ' $b$ ' coefficients on the final ET $\left(\mathrm{mm} \mathrm{h}^{-1}\right)$ value.

\begin{tabular}{|c|c|c|c|c|c|}
\hline \multirow[t]{2}{*}{ Image acquisition date } & \multirow[t]{2}{*}{ Statistics } & \multicolumn{2}{|c|}{ Irrigated fields } & \multicolumn{2}{|c|}{ Dryland fields } \\
\hline & & $\mathrm{NE}$ & SE & NW & SW \\
\hline \multirow[t]{2}{*}{26 June, 2008} & $\sigma$ & 0.04 & 0.04 & 0.03 & 0.03 \\
\hline & $\% \mathrm{CV}$ & 21.10 & 18.22 & 14.11 & 12.29 \\
\hline \multirow[t]{2}{*}{12 July, 2008} & $\sigma$ & 0.08 & 0.08 & 0.11 & 0.11 \\
\hline & $\% \mathrm{CV}$ & 21.02 & 21.88 & 79.93 & 68.52 \\
\hline \multirow[t]{2}{*}{20 July, 2008} & $\sigma$ & 0.04 & 0.04 & 0.05 & 0.05 \\
\hline & $\% \mathrm{CV}$ & 6.70 & 8.59 & 21.25 & 19.21 \\
\hline \multirow[t]{2}{*}{28 July, 2008} & $\sigma$ & 0.01 & 0.01 & 0.02 & 0.02 \\
\hline & $\% \mathrm{CV}$ & 0.74 & 1.18 & 5.60 & 5.17 \\
\hline \multirow[t]{2}{*}{05 August, 2008} & $\sigma$ & 0.00 & 0.00 & 0.01 & 0.01 \\
\hline & $\% \mathrm{CV}$ & 0.12 & 0.06 & 4.33 & 4.23 \\
\hline
\end{tabular}

$\sigma=$ standard deviation, \%CV = coefficient of variation in percentage.

accuracy (27.1\% RMSE) that Tasumi et al. [55] reported for semiarid Idaho conditions in their comparison of $\mathrm{ET}_{i}$ versus lysimeter values using Landsat imagery. In a comprehensive evaluation study by the SEBAL developer, the overall accuracy of daily ET for scale of the order of 100 ha has been reported as $\pm 15 \%$, further stating that time and space integration would improve accuracy [1]. SEBAL ET estimates explained $86 \%$ of the variability in the observed lysimeter data with slope close to unity (0.98) and an intercept of $-0.11 \mathrm{~mm} \mathrm{~h}^{-1}$, both significant at the 0.05 probability level (Fig. 5).

The evaluation of SEBAL model for irrigated and dryland lysimeter fields with the high resolution imagery revealed an interesting bias in the model's performance for the two agricultural water management regimes. The $\mathrm{ET}_{i}$ from the irrigated fields showed an RMSE of $0.14 \mathrm{~mm} \mathrm{~h}^{-1}$ contributing to $21.5 \%$ error, however, the dryland fields gave an RMSE of $0.15 \mathrm{~mm} \mathrm{~h}^{-1}$ which accounted for $39.5 \%$ error, nearly double the error as compared to the irrigated field. The NSE value for the dryland field $\mathrm{ET}_{i}$ estimates was -0.81 and $R^{2}$ was 0.35 , as compared to NSE of 0.55 and $R^{2}$ of 0.95 from the irrigated field. Clearly, the biased performance of SEBAL for dryland conditions affected the overall performance.
Similar gross under prediction results in relatively dry areas are reported by Timmermans et al. [6], Gowda et al. [56], and Gao and Long [7]. Timmermans et al. [6] made unsuccessful attempt to fix this problem by adjusting the end-member temperatures and momentum roughness length. In their study, they articulated that errors in $H$ estimation over sparsely vegetated surfaces in single source models can be reduced by adjusting the $k B^{-1}$ parameter.

\subsection{SEBAL with $\mathrm{kB}^{-1}$ parameterization}

Overall underperformance of SEBAL with variable accuracies for irrigated and dryland crops could be attributed to one or a combination of reasons. In the present agriculture dominant landscape with no forest cover and flat topography, the empirical parameterization of $z_{\text {om }}$ could not be the reason for deviations in ET estimates. At the same time, the aircraft image covered a small area with a relatively less heterogeneous landscape, hence the assumption of linearity of $d T$ versus $T_{s}$ could be considered valid. However, there are no studies to prove that the $d T$ versus $T_{S}$ linearity assumption could adequately address the spatial variation of $z_{o h}\left(k B^{-1}\right)$, or in other words address the differences between $T_{o}$ and $T_{s}$; we believe that this could be a reason for the biased results.

Results of SEBAL model estimates with $k B^{-1}$ parameterization showed improvement in the $\mathrm{ET}_{i}$ estimation (Fig. 6). Overall RMSE of $0.08 \mathrm{~mm} \mathrm{~h}^{-1}(16.3 \%)$ and MBE of $-0.02 \mathrm{~mm} \mathrm{~h}^{-1}$ (-3.6\%) were observed for the complete dataset (Table 5b). A 1:1comparison of Tables $5 \mathrm{a}$ and $5 \mathrm{~b}$ clearly indicates that the SEBAL with $k B^{-1}$ parameterization substantially improved its performance in estimating $\mathrm{ET}_{i}$. The overall underestimation errors decreased considerably from $24 \%$ to $-3.6 \%$ (PBIAS). This can be seen clearly in plots of $\mathrm{ET}_{i}$ for the irrigated and dryland field separately with and without the $k B^{-1}$ modifications (Figs. 5 and 6). Underestimated $\mathrm{ET}_{i}$ associated with partial canopy covers, moved closer to the observed values after the introduction of $k B^{-1}$ parameterization, while it did not affect the higher $\mathrm{ET}_{i}$ estimates associated with near complete canopy cover in the irrigated fields. This could be explained from

Table 5a

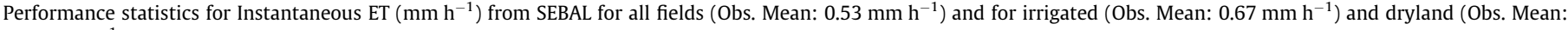
$0.40 \mathrm{~mm} \mathrm{~h}^{-1}$ ) fields separately.

\begin{tabular}{|c|c|c|c|c|c|c|c|c|c|c|}
\hline \multirow[t]{2}{*}{ Observation points } & \multirow[t]{2}{*}{$n$} & \multirow[t]{2}{*}{ Mean } & \multirow[t]{2}{*}{ MBE } & \multirow[t]{2}{*}{ PBIAS } & \multirow[t]{2}{*}{ RMSE } & \multirow[t]{2}{*}{ \%RMSE } & \multirow[t]{2}{*}{ NSE } & \multicolumn{3}{|c|}{ Regression } \\
\hline & & & & & & & & $R^{2}$ & $m$ & $y$-intercept \\
\hline All fields & 20 & 0.41 & 0.13 & 23.82 & 0.15 & 28.15 & 0.55 & 0.88 & 0.98 & -0.12 \\
\hline Irrigated field & 10 & 0.54 & 0.13 & 19.38 & 0.14 & 21.48 & 0.55 & 0.95 & 1.14 & -0.23 \\
\hline Dryland field & 10 & 0.27 & 0.12 & 31.44 & 0.16 & 39.55 & -0.80 & 0.35 & 0.41 & 0.11 \\
\hline
\end{tabular}




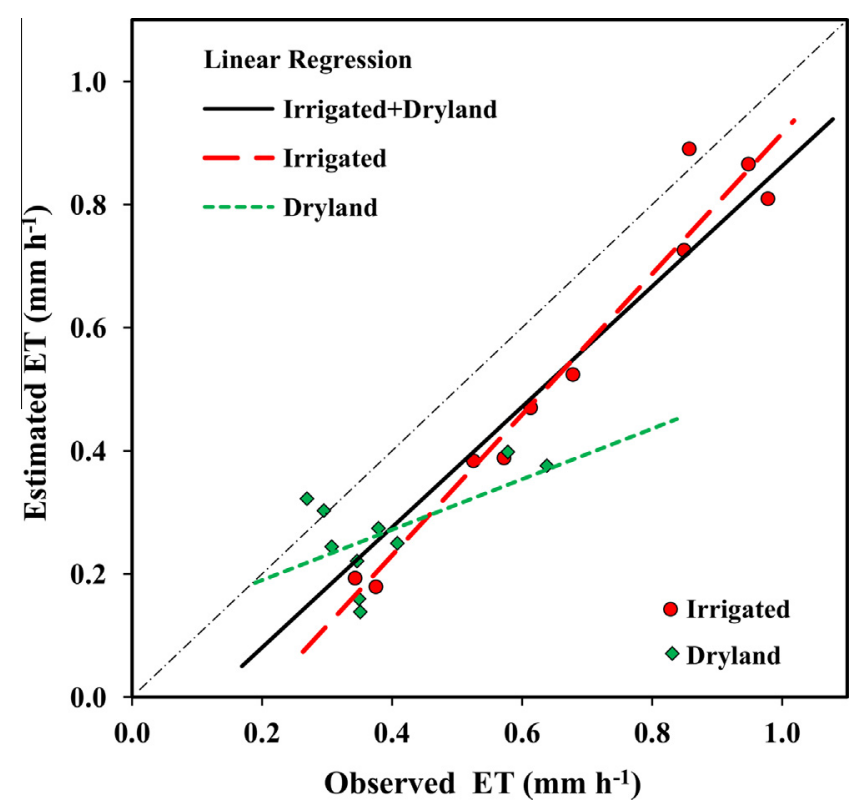

Fig. 5. SEBAL modeled versus observed instantaneous ET comparison for cotton fields under dryland and irrigation management.

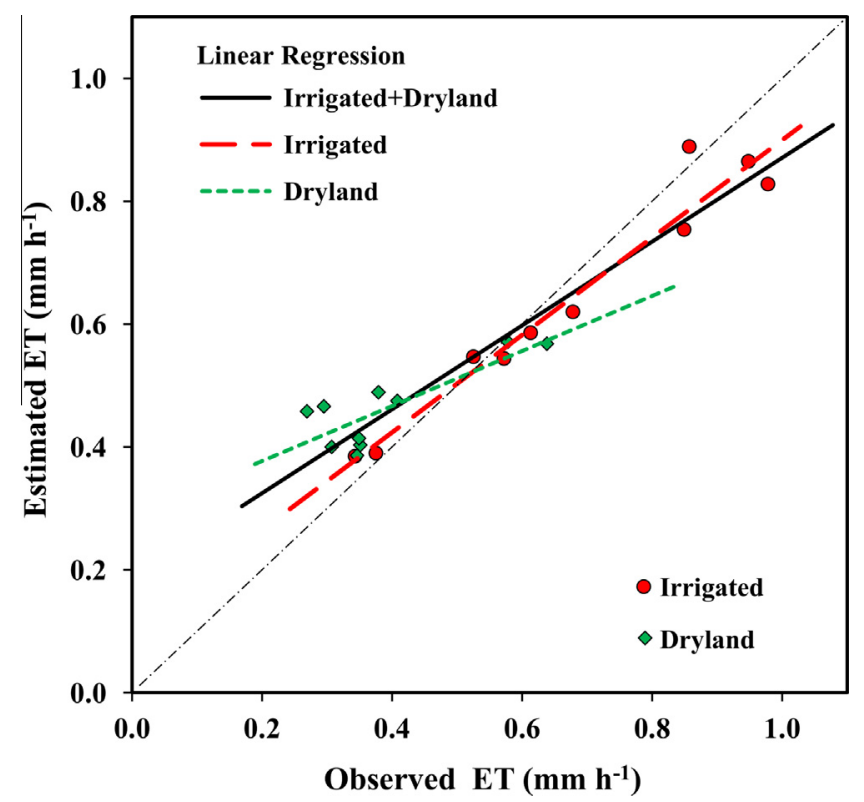

Fig. 6. SEBAL with $k B^{-1}$ parameterization modeled ET versus observed instantaneous ET comparison for cotton fields under dryland and irrigation management.

Fig. 2, where the images under analysis are from early crop stage to near complete canopy cover stage; hence, a sparse vegetation condition existed in most images. A nominal $k B^{-1}$ value of 2.3 did not work well under sparse vegetation conditions and generated lower $\mathrm{ET}_{i}$ estimates. SEBAL is known to have problems estimating ET un- der dry and sparse vegetation conditions [6,7]. Under these conditions, the difference between $T_{s}$ and $T_{o}$ was relatively large, and this could not be adequately addressed by the nominal $k B^{-1}$ value of 2.3 , whereas the converse was true for complete canopies. Therefore, the improvement in the $\mathrm{ET}_{i}$ estimates was solely due to an appropriate representation of spatially variable roughness length for heat transport $\left(z_{o h}\right)$. Table 6 gives a comprehensive list of aerodynamic roughness parameter estimates from the four fields. Marked difference in the $z_{\text {oh }}$ values with and without $k B^{-1}$ parameterization was observed.

3.5. Roughness length for momentum transport, excess resistance, and roughness length for heat transport

Questions have been raised about the simplistic approach of determining the complex roughness length for momentum transport $\left(z_{o m}\right)$ from the empirical relationship, Eq. (16), as a function of NDVI $[6,19]$. SEBAL developers suggested deriving local coefficients for the $z_{o m}$ relationship from the observed plant height over varied canopy structure. Although the requirements of plant height add to the inputs, our results show that the relationship generated realistic $z_{\text {om }}$ values under the present agricultural landscape setup (Table 6). Furthermore, applying a single pair of coefficients for the $z_{\text {om }}$ relationship (derived from the Tomelloso super site, Cas de Las Carascas, Spain [5]) for all the images did not result in any noticeable difference in the $\mathrm{ET}_{i}$ estimation; however, we must caution that the Tomelloso super site was also an agricultural region, and these coefficients cannot be universally applied. The $z_{\text {om }}$ values compared well with the estimates obtained over an incomplete canopy cover of cotton using the profile method [33]. Also, the $z_{\text {om }}$ values were comparable with the Brutsaert [53] relationship $\left(z_{\text {om }}=0.13 \mathrm{~h}\right)$ (Table 6$)$.

The $k B^{-1}$ parameter representing the excess resistance to heat transfer has been a matter of controversy since its inception into the single source model. Nevertheless, the term cannot be avoided because it accounts for the fact that $T_{s}$ is frequently greater than $T_{o}$ [31]. In this study, the parameterized $k B^{-1}$ values produced more accurate $\mathrm{ET}_{i}$ estimates compared with the constant $k B^{-1}$ value of 2.3 proposed by the SEBAL developers. The value for $k B^{-1}$ for all four lysimeter fields is presented in Table 6 . The value of $k B^{-1}$ varied between 2 and 13 for most cases, with higher values associated with low canopy cover conditions. On 26 June, exceptionally high $k B^{-1}$ values were found due to the fact that image was acquired early in the cropping season when the surface was bare soil with isolated cotton seedlings (see Fig. 2); such a surface is classified as bluff rough element with no consensus on appropriate $k B^{-1}$ value [29]. The $k B^{-1}$ value for the irrigated fields were always less than that in the dryland fields (Table 6). This is because, at any point during the cropping season, irrigated fields had larger canopy cover than the dryland fields. Consequently, the value of around 2.3 was suitable for irrigated fields when the crop attained near complete canopy cover conditions. The minimum value of $k B^{-1}$ for the dryland fields was 5.3, which was estimated with the $5 \mathrm{Au}-$ gust image. These results corroborate the conclusions from numerous studies on the excess resistance parameter $\left(k B^{-1}\right)$, that: (i) over a sparsely vegetated surface, the difference between $T_{s}$ and $T_{o}$ can

Table 5b

Performance statistics for Instantaneous ET $\left(\mathrm{mm} \mathrm{h}^{-1}\right)$ computed from SEBAL with $k B^{-1}$ parameterization.

\begin{tabular}{|c|c|c|c|c|c|c|c|c|c|c|}
\hline \multirow[t]{2}{*}{ Observation points } & \multirow[t]{2}{*}{$n$} & \multirow[t]{2}{*}{ Mean } & \multirow[t]{2}{*}{ MBE } & \multirow[t]{2}{*}{ PBIAS } & \multirow[t]{2}{*}{ RMSE } & \multirow[t]{2}{*}{ \%RMSE } & \multirow[t]{2}{*}{ NSE } & \multicolumn{3}{|c|}{ Regression } \\
\hline & & & & & & & & $R^{2}$ & $m$ & $y$-intercept \\
\hline All fields & 20 & 0.55 & -0.02 & -3.56 & 0.08 & 16.27 & 0.85 & 0.92 & 0.68 & 0.19 \\
\hline Irrigated field & 10 & 0.64 & 0.03 & 4.89 & 0.07 & 10.15 & 0.89 & 0.95 & 0.79 & 0.12 \\
\hline Dryland field & 10 & 0.46 & -0.07 & -18.11 & 0.10 & 25.97 & 0.22 & 0.68 & 0.45 & 0.29 \\
\hline
\end{tabular}


Table 6

Aerodynamic roughness parameters for the four cotton fields under irrigation (NE and SE) and dryland (NW and SW) management.

\begin{tabular}{|c|c|c|c|c|c|c|c|c|c|}
\hline Date & Field & $z_{o m \_} D(\mathrm{~m})$ & $z_{o m \_} E(\mathrm{~m})$ & $z_{\text {oh_- }} C(\mathrm{~m})$ & $k B^{-1}(\mathrm{~m})$ & $z_{o h \_} S(\mathrm{~m})$ & $C_{-} h t(\mathrm{~m})$ & C_ht_O (m) & $z_{o m \_} B(\mathrm{~m})$ \\
\hline \multirow[t]{4}{*}{26 June } & $\mathrm{NE}$ & 0.011 & 0.009 & 0.0009 & 19.21 & 0.00001 & 0.084 & 0.152 & 0.020 \\
\hline & $\mathrm{SE}$ & 0.010 & 0.008 & 0.0008 & 24.67 & 0.00001 & 0.076 & 0.178 & 0.023 \\
\hline & NW & 0.008 & 0.007 & 0.0007 & 44.51 & 0.00001 & 0.063 & 0.089 & 0.012 \\
\hline & SW & 0.008 & 0.007 & 0.0007 & 58.86 & 0.00001 & 0.060 & 0.114 & 0.015 \\
\hline \multirow[t]{4}{*}{12 July } & $\mathrm{NE}$ & 0.052 & 0.044 & 0.0044 & 5.39 & 0.00026 & 0.382 & 0.457 & 0.059 \\
\hline & $\mathrm{SE}$ & 0.048 & 0.041 & 0.0041 & 5.55 & 0.00020 & 0.352 & 0.330 & 0.043 \\
\hline & NW & 0.018 & 0.015 & 0.0015 & 8.54 & 0.00001 & 0.137 & 0.356 & 0.046 \\
\hline & SW & 0.026 & 0.022 & 0.0022 & 6.99 & 0.00003 & 0.190 & 0.292 & 0.038 \\
\hline \multirow[t]{4}{*}{20 July } & $\mathrm{NE}$ & 0.082 & 0.102 & 0.0102 & 3.50 & 0.00268 & 0.602 & 0.559 & 0.073 \\
\hline & SE & 0.073 & 0.092 & 0.0092 & 3.65 & 0.00213 & 0.540 & 0.406 & 0.053 \\
\hline & NW & 0.009 & 0.011 & 0.0011 & 13.04 & 0.00001 & 0.066 & 0.432 & 0.056 \\
\hline & SW & 0.019 & 0.025 & 0.0025 & 6.55 & 0.00008 & 0.142 & 0.356 & 0.046 \\
\hline \multirow[t]{4}{*}{28 July } & $\mathrm{NE}$ & 0.123 & 0.182 & 0.0182 & 2.78 & 0.00780 & 0.902 & 0.559 & 0.073 \\
\hline & SE & 0.115 & 0.168 & 0.0168 & 2.86 & 0.00717 & 0.843 & 0.610 & 0.079 \\
\hline & NW & 0.012 & 0.013 & 0.0013 & 11.87 & 0.00001 & 0.087 & 0.508 & 0.066 \\
\hline & SW & 0.021 & 0.024 & 0.0024 & 6.78 & 0.00007 & 0.153 & 0.457 & 0.059 \\
\hline \multirow[t]{4}{*}{05 August } & $\mathrm{NE}$ & 0.146 & 0.265 & 0.0265 & 2.18 & 0.01662 & 1.073 & 0.635 & 0.083 \\
\hline & $\mathrm{SE}$ & 0.199 & 0.401 & 0.0401 & 2.02 & 0.02684 & 1.468 & 0.559 & 0.073 \\
\hline & NW & 0.017 & 0.016 & 0.0016 & 8.53 & 0.00003 & 0.126 & 0.533 & 0.069 \\
\hline & SW & 0.028 & 0.030 & 0.0030 & 5.32 & 0.00023 & 0.207 & 0.432 & 0.056 \\
\hline MEAN & & 0.051 & 0.074 & 0.0074 & 12.14 & 0.00321 & 0.378 & 0.401 & 0.052 \\
\hline
\end{tabular}

$z_{\text {om_ }} D=$ Roughness length for momentum estimated from Eq. (16) using coefficients derived for each image as given in Fig. 3.

$z_{\text {om }} E=$ Roughness length for momentum estimated from Eq. (16) using constant coefficients $C_{1}=-5.5$ and $C_{2}=5.8$, from [5].

$z_{\text {oh_ }} C=$ Roughness length for heat estimated from Eq. (15) using constant $k B^{-1}$ value of 2.3 .

$k B^{-1}=$ Excess resistance parameter for heat transfer estimated from parameterization given by Su et al. [30], Appendix B.

$z_{\text {oh_ }} S=$ Roughness length for heat estimated from Eq. (15) using $k B^{-1}$ value from Su et al. [30], Appendix B.

$C \_h t=$ Canopy height from Eq. (A2) $\left(=z_{\text {om }} D / 0.13\right)$.

C_ht_O = Field measurement of canopy height.

$z_{o m \_} B=$ Roughness length for momentum estimated from Brutsaert relationship, Eq. (A2) $\left(=0.13 * C \_h t \_O\right)$.

exceed $10{ }^{\circ} \mathrm{C}[49]$, so an adjustment is required (through $k B^{-1}$ ), (ii) $k B^{-1}$ value should range from 1 to 10 , to obtain accurate estimates of $H$ [32,33], and (iii) $H$ is more sensitive to $k B^{-1}$ value of 2 than a value of about 6 [29].

Roughness length for heat transport, $z_{o h}$, expressed in terms of $k B^{-1}\left[z_{o h}=z_{\text {om }} / \exp \left(k B^{-1}\right)\right]$ for four lysimeter fields over the five image acquisition dates are presented in Table 6. Comparison of $z_{\text {oh }}$ values obtained from $k B^{-1}$ parameterization and a constant $k B^{-1}$ (of 2.3) reveals significant differences. To address the high $k B^{-1}$ values obtained for the sparse vegetation conditions, we restricted the lower limit of $z_{\text {oh }}$ to $10^{-5} \mathrm{~m}$.

\section{Conclusions}

SEBAL is thoroughly evaluated using extensive crop characterization, ET, and high resolution remote sensing datasets acquired during the BEAREX08. The main distinguishing feature of this study was the simultaneous evaluation of SEBAL for both irrigated and dryland crops covering a range of conditions from sparse vegetation to near complete canopy cover. This study also examined the issues of subjective selection of extreme pixels, dealt with aerodynamic roughness parameters, and showed improvement in ET estimates through the introduction of $k B^{-1}$ parameterization into the SEBAL model. On an average $20 \%$ uncertainty in term of $\mathrm{CV}$ was observed as a result of subjectivity in the end member selection process. The sensitivity to end member pixel selection is crucial to the performance of SEBAL; hence, a clear methodology for the selection process is required to remove the subjective decision and make the process more robust. A rigorous sensitivity analysis of the ' $a$ ' and ' $b$ ' coefficients estimation in the temperature gradient relationship is necessary because this forms the backbone of SEBAL. SEBAL ET ${ }_{i}$ estimates compared reasonably well against the lysimeter values with underestimation error and RMSE close to $0.15 \mathrm{~mm} \mathrm{~h}^{-1}$ (28\%). Errors were relatively small for the irrigated fields as compared with the dryland fields. Modifying the SEBAL algorithm by introducing $k B^{-1}$ parameterization considerably improved the accuracy of $\mathrm{ET}_{i}$ estimation, with an overall RMSE of
$0.08 \mathrm{~mm} \mathrm{~h}^{-1}(16 \%)$. It can be concluded that the temperature gradient $(d T)$ linear relationship does not have any component to consider for the differences arising due to use of $T_{S}$ for $T_{o}$ and hence a realistic correction factor in the form of $k B^{-1}$ has to be incorporated into SEBAL. Furthermore, a $k B^{-1}$ value of 2.3 would grossly underestimate ET for sparse vegetation conditions. Locally calibrated coefficients for the aerodynamic roughness parameters are crucial to the performance of the algorithm. SEBAL is a physically based algorithm, but the numerous empirical sub-models and requirement for image specific calibrations, limits its operational capabilities. Nevertheless, results of the present study with the suggested improvements in the algorithm make it a viable tool for regional scale ET mapping. The temperature gradient approach ( $d T$ estimation) is a novel approach indigenous to the SEBAL algorithm, however, the underlying assumptions are many necessitating a detailed sensitivity study.

\section{Acknowledgments}

This research was supported by the Ogallala Aquifer Program, a consortium between USDA - Agricultural Research Service, Kansas State University, Texas AgriLife Research, Texas AgriLife Extension Service, Texas Tech University, and West Texas A\&M University. This is contribution number 12-284-J from the Kansas Agricultural Experiment Station.

EEO/Non-Discrimination Statement: The US Department of Agriculture (USDA) prohibits discrimination in all its programs and activities on the basis of race, color, national origin, age, disability, and where applicable, sex, marital status, familial status, parental status, religion, sexual orientation, genetic information, political beliefs, reprisal, or because all or part of an individual's income is derived from any public assistance program. (Not all prohibited bases apply to all programs.) Persons with disabilities who require alternative means for communication of program information (Braille, large print, audiotape, etc.) should contact USDA's TARGET Center at (202) 720-2600 (voice and TDD). To file a complaint of discrimination, write to USDA, Director, Office of Civil Rights, 
1400 Independence Avenue, S.W., Washington, DC 20250-9410, or call (800) 795-3272 (voice) or (202) 720-6382 (TDD). USDA is an equal opportunity provider and employer.

\section{Appendix A.}

Various intermediate parameterizations used in the SEBAL algorithm.

Displacement height was computed from the model given by Verhoef et al. [57]:

$d_{o}=h\left(1-\frac{1-e^{-\sqrt{c_{1} \cdot \mathrm{LAI}}}}{\sqrt{c_{1 \cdot \mathrm{LAI}}}}\right)$

where $h$ is the canopy height and $c_{1}$ is a free parameter with the value 20.6 .

Roughness length for momentum transport as given by Brutsaert [53]:

$z_{\text {om }}=0.13 h$

Leaf Area Index model developed specifically for the Texas High Plains region given by Gowda et al. [58]:

$\mathrm{LAI}=8.768 \times \mathrm{NDVI}^{3.616}$

Fractional cover was derived from relationship taken from Jia et al. [51]:

$f_{c}=1-\left[\frac{\mathrm{NDVI}-\mathrm{NDVI}_{\max }}{\mathrm{NDVI}_{\min }-\mathrm{NDVI}_{\max }}\right]^{K}$

where $K$ is taken as 0.4631 .

Wind speed at blending height

$u_{b}=u_{r e f}\left[\frac{\ln \left(z_{b}-d_{o}\right)-\ln \left(z_{o m}\right)}{\ln \left(z_{r e f}-d_{o}\right)-\ln \left(z_{o m}\right)}\right]$

Monin Obukhov Length $(L)$

$L=-\frac{\rho_{a} C_{p} u_{*}^{3} T_{s}}{k g H}$

where density of air $\left(\rho_{a}\right)=\sim 1.17 \mathrm{~kg} \mathrm{~m}^{-3}$, specific heat capacity of air $\left(C_{p}\right)=\sim 1.005 \mathrm{~J} \mathrm{~kg}^{-1} \mathrm{~K}^{-1}$, gravitational acceleration $(g)=$ $9.81 \mathrm{~m} \mathrm{~s}^{-2}$.

Momentum transfer correction factor under unstable condition from Paulson [36]:

$\psi_{m}=2 \ln \left[\frac{1+x_{m}}{2}\right]+\ln \left[\frac{1+x_{m}^{2}}{2}\right]-2 \arctan \left(x_{m}\right)+\frac{\pi}{2}$

where $x_{m}$ is defined as:

$x_{m}=\left(1-16 \frac{z_{b}-d_{o}}{L}\right)^{0.25}$

Heat transfer correction factor under unstable condition from Paulson [36]:

$\psi_{h}=2 \ln \left[\frac{1+x_{h}^{2}}{2}\right]$

where $x_{h}$ is defined as:

$x_{h}=\left(1-16 \frac{z_{\text {ref }}-d_{0}}{L}\right)^{0.25}$

\section{Appendix B.}

Excess resistance to heat transfer formulation as given by Su.et al. [49] $k B^{-1}=\frac{k C_{d}}{4 C_{t} \frac{u_{*}}{u(h)}\left(1-e^{-n_{e c} / 2}\right)} f_{c}^{2}+\frac{k \cdot \frac{u_{*}}{u(h)} \cdot \frac{z_{o m}}{h}}{C_{t}^{*}} f_{c}^{2} f_{s}^{2}+k B_{s}^{-1} f_{s}^{2}$

In Eq. (B1), $k B_{s}^{-1}$ is the bare soil surface excess resistance computed as:

$k B_{s}^{-1}=2.46\left(R e_{*}\right)^{1 / 4}-\ln (7.4)$

In Eq. (B1), $n_{e c}$ is within-canopy wind speed profile extinction coefficient given by:

$n_{e c}=\frac{C_{d} \cdot \text { LAI }}{2 u_{*}^{2} / u(h)^{2}}$

In Eq. (B1) and (B3), the ratio $u_{*} / u(h)$ is parameterized as:

$\frac{u_{*}}{u(h)}=c_{1}-c_{2} \cdot e^{-c_{3} \cdot C_{d} \cdot \text { LAI }}$

where $c_{1}=0.320, c_{2}=0.264$ and $c_{3}=15.1$.

In Eq. (B1), $C_{t}^{*}$ is heat transfer coefficient of the soil given as:

$C_{t}^{*}=\operatorname{Pr}^{-2 / 3} \operatorname{Re}_{*}^{-1 / 2}$

In Eq. (B2) and Eq. (B5), $R e_{*}$ is roughness Reynolds number calculated as:

$\operatorname{Re}_{*}=h_{s} u_{*} / v$

where $h_{s}$ is the roughness height for soil taken here as $0.009 \mathrm{~m}$.

In Eq. (B1), $v$ is kinematic viscosity of the given by:

$v=1.327 \times 10^{-5}\left(p_{0} / p\right)\left(T_{a} / T_{a 0}\right)^{1.81}$

where, $p$ and $T_{a}$ are ambient pressure and temperature and $p_{o}=101.3 \mathrm{kPa}$ and $T_{a o}=273.15 \mathrm{~K}$

Other terms in Eqs. (B1)-(B7) are: $C_{d}$ is the drag coefficient of the foliage elements taken as $0.2, C_{t}$ is heat transfer coefficient of the leaf with value $0.01, P_{r}$ is Prandtl number with value 0.71 , $u(h)$ is the horizontal wind speed at the canopy height, $f_{c}$ is the fractional canopy coverage and $f_{s}$ is its compliment, and $k$ is von Karman's constant taken as 0.41 .

\section{References}

[1] Bastiaanssen WGM, Noordman EJM, Pelgrum H, Davids G, Thoreson BP, Allen RG. SEBAL model with remotely sensed data to improve water-resources management under actual field conditions. J Irrig Drain Eng 2005;131:85-93. http://dx.doi.org/10.1061/(ASCE)0733-9437(2005)131:1(85).

[2] Allen RG, Pereira LS, Howell TA, Jensen ME. Evapotranspiration information reporting: I. Factors governing measurement accuracy. Agric Water Manage 2011;98:899-920. http://dx.doi.org/10.1016/j.agwat.2010.12.015.

[3] Howell TA, Schneider AD, Dusek DA, Marek TM, Steiner JL. Calibration and scale performance of bushland weighing lysimeters. Trans ASAE 1995;38:1019-24.

[4] Allen RG, Pereira LS, Howell TA, Jensen ME. Evapotranspiration information reporting: II. Recommended documentation. Agric Water Manage 2011;98:921-9. http://dx.doi.org/10.1016/j.agwat.2010.12.016.

[5] Bastiaanssen WGM. Regionalization of surface flux densities and moisture indicators in composite terrain. Ph.D. thesis, Wageningen Agriculture University, 1995.

[6] Timmermans WJ, Kustas WP, Anderson MC, French AN. An intercomparison of the surface energy balance algorithm for land (SEBAL) and the two-source energy balance (TSEB) modeling schemes. Remote Sens Environ 2007;108:369-84. http://dx.doi.org/10.1016/j.rse.2006.11.028.

[7] Gao Y, Long D. Intercomparison of remote sensing-based models for estimation of evapotranspiration and accuracy assessment based on SWAT. Hydrol Process 2008;22:4850-69. http://dx.doi.org/10.1002/hyp.7104.

[8] Singh RK, Irmak A, Irmak S, Martin DL. Application of SEBAL model for mapping evapotranspiration and estimating surface energy fluxes in south-central Nebraska. J Irrig Drain Eng 2008;134:273-85. http://dx.doi.org/10.1061/ (ASCE)0733-9437(2008)134:3(273)

[9] Choi M, Kustas WP, Anderson MC, Allen RG, Li F, Kjaersgaard JH. An intercomparison of three remote sensing-based surface energy balance algorithms over a corn and soybean production region (Iowa, US) during SMACEX 2009. Agric For Meteorol 2009;149:2082-97. http://dx.doi.org/ 10.1016/j.agrformet.2009.07.002. 
[10] Long D, Singh VP. A modified surface energy balance algorithm for land (MSEBAL) based on a trapezoidal framework. Water Resour Res 2012;48:W02528. http://dx.doi.org/10.1029/2011WR010607.

[11] Gowda PH, Chavez JL, Colaizzi PD, Evett SR, Howell TA, Tolk JA. ET mapping for agricultural water management: present status and challenges. Irrig Sci 2008;26:223-37. http://dx.doi.org/10.1007/s00271-007-0088-6.

[12] Kalma JD, McVicar TR, McCabe MF. Estimating land surface evaporation: a review of methods using remotely sensed surface temperature data. Surv Geophys 2008;29:421-69. http://dx.doi.org/10.1007/s10712-008-9037-z.

[13] Li ZL, Tang R, Wan Z, Bi Y, Zhou C, Tang B. A review of current methodologies for regional evapotranspiration estimation from remotely sensed data. Sensors 2009;9:3801-53. http://dx.doi.org/10.3390/s90503801.

[14] Allen RG, Tasurmi M, Morse AT, Trezza R. A landsat-based energy balance and evapotranspiration model in western US water rights regulation and planning. Irrig Drain Syst 2005;19:251-68. http://dx.doi.org/10.1007/s10795-005-5187z.

[15] Senay GB, Budde ME, Verdin JP, Melesse AM. A coupled remote sensing and simplified surface energy balance approach to estimate actual evapotranspiration from irrigated fields. Sensors 2007;7:979-1000. http:// dx.doi.org/10.3390/s7060979.

[16] Elhaddad Ayman, Garcia Luis A. Surface energy balance-based model for estimating evapotranspiration taking into account spatial variability in weather. J Irrig Drain Eng 2008;134:681-9. http://dx.doi.org/10.1061/ (ASCE)0733-9437(2008)134:6(681).

[17] Gao ZQ, Liu CS, Gao W, Chang NB. A coupled remote sensing and the surface energy balance with topography algorithm (SEBTA) to estimate actual evapotranspiration over heterogeneous terrain. Hydrol Earth Syst Sci 2011;15:119-39. http://dx.doi.org/10.5194/hess-15-119-2011.

[18] Bastiaanssen W, Thoreson B, Clark B, David G. Discussion of "Application of SEBAL model for mapping evapotranspiration and estimating surface energy fluxes in south-central Nebraska" by R.K. Singh, Ayse Irmak, Suat Irmak, Derrel L. Martin. J Irrig Drain Eng 2010;134:282-3. http://dx.doi.org/10.1061/ (ASCE)IR.1943-4774.0000216.

[19] Norman JM, Anderson MC, Kustas WP. Are single-source, remote-sensing surface-flux models too simple? In: D'Urso G, Jochum MAO, Moreno J, editors. Proceedings of the international conference on earth observation for vegetation monitoring and water management, vol. 852. American Institute of Physics; 2006. p. 170-7.

[20] Bastiaanssen WGM, Menenti M, Feddes RA, Holtslag AAM. A remote sensing surface energy balance algorithm for land (SEBAL) 1. Formulation. J Hydrol 1998;213:198-212. http://dx.doi.org/10.1016/S0022-1694(98)00253-4.

[21] Bastiaanssen WGM. SEBAL-based sensible and latent heat fluxes in the irrigated Gediz Basin, Turkey. J Hydrol 2000;229:87-100. http://dx.doi.org/ 10.1016/S0022-1694(99)00202-4.

[22] Jacob F, Olioso A, Gu XF, Su Z, Seguin B. Mapping surface fluxes using airborne visible, near infrared, thermal infrared remote sensing data and a spatialized surface energy balance model. Agronomie 2002;22:669-80. http://dx.doi.org/ 10.1051/agro:2002053.

[23] Bastiaanssen WGM, Ahmad MD, Chemin Y. Satellite surveillance of evaporative depletion across the Indus Basin. Water Resour Res 2002;38:1273-81. http://dx.doi.org/10.1029/2001WR000386.

[24] Wang J, Sammis TW, Gutschick VP, Gebremichael M, Miller DR. Sensitivity analysis of the surface energy balance algorithm for land (SEBAL). Trans ASABE 2009;52:801-11.

[25] Gieske Ambro, Meijninger Wouter. High density NOAA time series of ET in the Gediz Basin, Turkey. Irrig Drain Syst 2005;19:285-99. http://dx.doi.org/ 10.1007/s10795-005-5191-3.

[26] Chandrapala Lalith, Wimalasuriya Malika. Satellite measurement supplemented with meteorological data to operationally estimate evapotranspiration in Sri Lanka. Agric Water Manage 2003;58:89-107. http://dx.doi.org/10.1016/S0378-3774(02)00127-0.

[27] Allen RG, Bastiaanssen WGM, Tasumi M, Morse A, Evapotranspiration on the watershed scale using the SEBAL model and landsat images. ASAE Meeting Paper No.01-2224 St. Joseph, Mich; 2001.

[28] Long D, Singh VP, Li ZL. How sensitive is SEBAL to changes in input variables, domain size and satellite sensor. J Geophys Res 2011;116:D21107. http:// dx.doi.org/10.1029/2011JD016542.

[29] Verhoef A, De Bruin HAR, Van Den Hurk BJJM. Some practical notes on the parameter $\mathrm{kB}^{-1}$ for sparse vegetation. J Appl Meteorol 1997;36:560-72. http:// dx.doi.org/10.1175/1520-0450(1997)036<0560:SPNOTP>2.0.CO;2.

[30] Su Z, Schmugge T, Kustas WP, Massman WJ. An evaluation of two models for estimation of the roughness height for heat transfer between the land surface and the atmosphere. J Appl Meteorol 2001;40:1933-51. http://dx.doi.org/ 10.1175/1520-0450(2001)040<1933:AEOTMF>2.0.CO;2

[31] Lhomme JP, Chehbouni A, Monteny B. Sensible heat flux-radiometric surface temperature relationship over sparse vegetation: Parameterizing $\mathrm{B}^{-1}$. Bound Layer Meteorol 2000;97:431-57. http://dx.doi.org/10.1023/A:1002786 402695 .

[32] Stewart JB, Kustas WP, Humes KS, Nichols WD, Moran MS, De Bruin HAR. Sensible heat flux-radiometric surface temperature relationship for eight semi arid areas. J Appl Meteorol 1994;33:1110-7.

[33] Kustas WP, Choudhury BJ, Moran MS, Reginato RJ, Jackson RD, Gay LW, Weaver HL. Determination of sensible heat flux over sparse canopy using thermal infrared data. Agric For Meteorol 1989;44:197-216. http://dx.doi.org/10.1016 0168-1923(89)90017-8.

[34] Kustas WP, Anderson MC, Norman JM, Li F. Utility of radiometric-aerodynamic temperature relations for heat flux estimation. Bound Layer Meteoro 2007;122:167-87. http://dx.doi.org/10.1007/s10546-006-9093-1.

[35] Jia L, Su Z, van den Hurk B, Menenti M, Moene A, De Bruin HAR, et al Estimation of sensible heat flux using the surface energy balance system (SEBS) and ATSR measurements. Phys Chem Earth Part B 2003;28:75-88. http://dx.doi.org/10.1016/S1474-7065(03)00009-3.

[36] Kustas W, Anderson M. Advances in thermal infrared remote sensing for land surface modeling. Agric For Meteorol 2009;149:2071-81. http://dx.doi.org 10.1016/j.agrformet.2009.05.016.

[37] Jackson TJ, Vine DML, Hsu AY, Oldak A, Starks PJ, Swift CT, et al. Soil moisture mapping at regional scales using microwave radiometry: the southern great plains hydrology experiment. IEEE Trans Geosci Remote Sens 1999;37:2136-51. http://dx.doi.org/10.1109/36.789610.

[38] Su Z, Timmermans WJ, van der Tol C, Dost R, Bianchi R, Ǵomez JA, et al. EAGLE 2006 - Multi-purpose, multi-angle and multi-sensor in-situ and airborne campaigns over grassland and forest. Hydrol Earth Syst Sci 2009;13:833-45.

[39] Su Z, Timmermans W, Gieske A, Jia L, Elbers JA, Olioso A, et al. Quantification of land atmosphere exchanges of water, energy and carbon dioxide in space and time over the heterogeneous Barrax site. Int J Remote Sens 2008;29:5215-35. http://dx.doi.org/10.1080/01431160802326099.

[40] Sobrino JA, Muñoz JJC, Sòria G, Gómez M, Ortiz AB, Romaguera M, et al Thermal remote sensing in the framework of the SEN2FLEX project: field measurements, airborne data and applications. Int J Remote Sens 2008;29:4961-91. http://dx.doi.org/10.1080/01431160802036516.

[41] Kustas WP, Jackson TJ, Prueger JH, Hatfield JL, Anderson MC. Remote sensing field experiments for evaluating soil moisture retrieval algorithms an modeling land-atmosphere dynamics in central Iowa. EOS Trans Am Geophys Union 2003;84:485-93.

[42] Tolk JA, Evett SR, Howell TA. Advection influences on evapotranspiration of Alfalfa in a semiarid climate. Agron J 2006;98:1646-54. http://dx.doi.org/ 10.2134/agronj2006.0031.

[43] Chávez JL, Gowda PH, Howell TA, Neale CMU, Copeland KS. Estimating hourly crop ET using a two-source energy balance model and multispectral airborne imagery. Irrig Sci 2009;2009(28):79-91. http://dx.doi.org/10.1007/s00271 009-0177-9

[44] Marek TH, Porter DO, Howell TA, Kenny N, Gowda, PH. Understanding ET and its use in irrigation scheduling (a TXHPET Network series user manual). Texas AgriLife Research at Amarillo, Publication No. 09-02, Texas A\&M University, Amarillo, 6 Texas; 2009. p. 60

[45] Neale CMU, Geli H, Kustas WP, Alfieri JG, Gowda PH, et al. Modeling the soil water content profile using a remote sensing based hybrid evapotranspiration modeling approach. Adv Water Resour 2012;50:152-61. http://dx.doi.org/ 10.1016/j.advwatres.2012.10.008.

[46] Brutsaert W. On a derivable formula for long-wave radiation from clear skies. Water Resour Res 1975;11:742-4

[47] Van de Griend AA, Owe M. On the relationship between thermal emissivity and normalized difference vegetation index for natural surfaces. Int J Remote Sens 1993;14:1119-31.

[48] Paulson CA. The mathematical representation of wind speed and temperature profiles in the unstable atmospheric surface layer. J Appl Meteorol 1970;9:856-61.

[49] Chehbouni A, Seen DL, Njoku EG, Monteny BM. Examination of the difference between radiative and aerodynamic surface temperatures over sparsely vegetated surfaces. Remote Sens Environ 1996;58:177-86.

[50] Kustas WP, Choudhury BJ, Kunkel KE, Gay LW. Estimation of the aerodynamic roughness parameters over an incomplete canopy cover of cotton. Agric For Meteorol 1989;46:91-105. http://dx.doi.org/10.1016/S0034-4257(96)00037-5.

[51] Chamberlain AC. Transport of gases to and from surfaces with bluff and wavelike roughness elements. Q J R Meteorol Soc 1968;94:318-32. http:/ dx.doi.org/10.1002/qj.49709440108.

[52] Beljaars ACM, Holtslag AAM. Flux parameterization over land surfaces for atmospheric models. J Appl Meteorol 1991:30:327-41. http://dx.doi.org 10.1175/1520-0450(1991)030<0327:FPOLSF>2.0.CO;2.

[53] Brutsaert W. Evaporation into the atmosphere. Holland: D. Reidel Pub. Co.; 1982.

[54] Field RT, Fritschen LJ, Kanemasu ET, Smith EA, Stewart JB, Verma SB, Kustas WP. Calibration, comparison, and correction of net radiation instruments used during FIFE. J Geophys Res 1992;18:681-95.

[55] Tasumi M, Trezza R, Allen RG, Wright JL. Operational aspects of satellite-based energy balance models for irrigated crops in the semi-arid US. Irrig Drain Syst 2005;19:355-76. http://dx.doi.org/10.1007/s10795-005-8138-9.

56] Gowda PH, Howell TA, Chavez JL, Copeland KS, Paul G. Comparing SEBAL ET with Lysimeter data in the semi-arid Texas High Plains. In: Proceedings of world environmental and water resources congress; 2008.

[57] Verhoef A, McNaughton KG, Jacobs AFG. A parameterization of momentum roughness length and displacement height for a wide range of canopy densities. Hydrol Earth Syst Sci 1997;1:81-91.

[58] Gowda PH, Chavez JL, Colaizzi PD, Howell TA, Schwartz RC. Relationship between LAI and Landsat TM spectral vegetation indices in the Texas Panhandle. In: proceedings of the ASABE annual meeting; 2007. 